Comf-9506126--3

UCRL-JC-120545

PREPRINT

\title{
Using Emissivity-Corrected Thermal Maps to Locate Deep Structural Defects in Concrete Bridge Decks
}

\author{
Nancy K. Del Grande \\ Phillip F. Durbin
}

This paper was prepared for submittal to the

SPIE Nondestructive Evaluation of Aging Bridges and Highways

Oakland, California

June 6-8, 1995

April 5, 1995

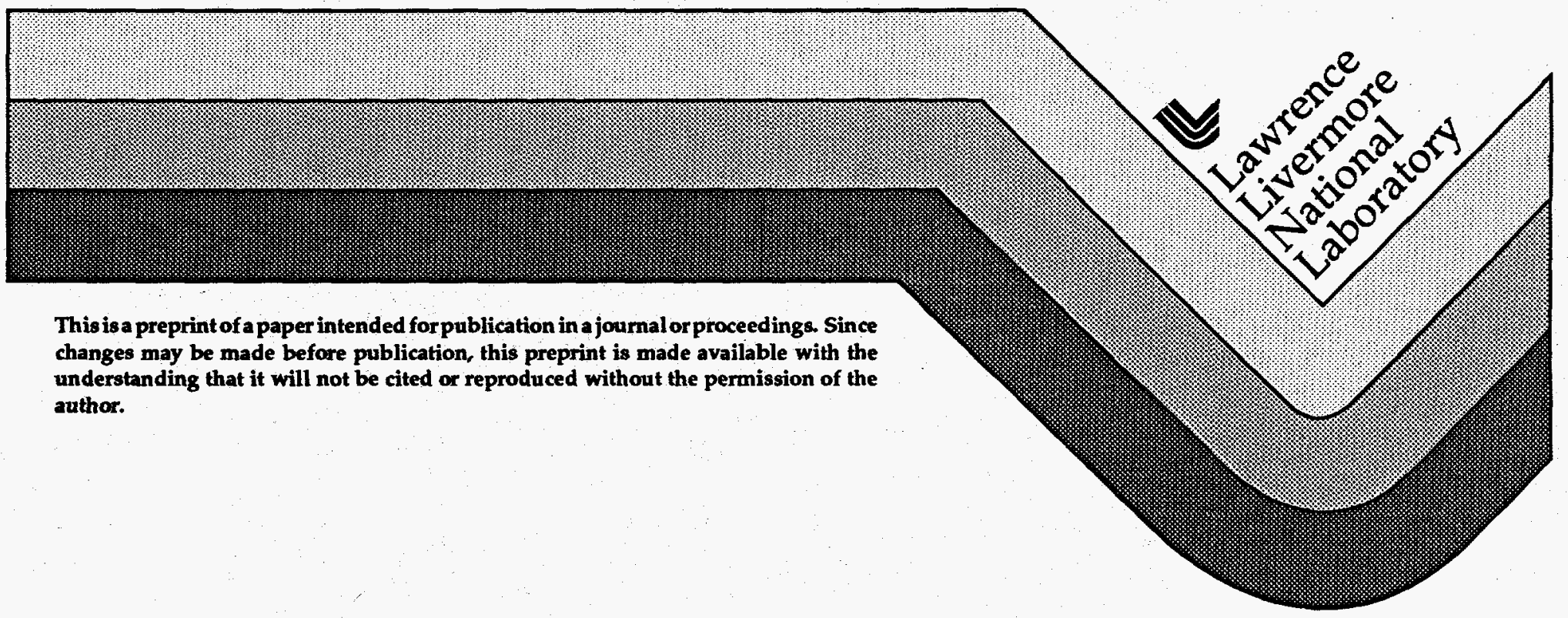




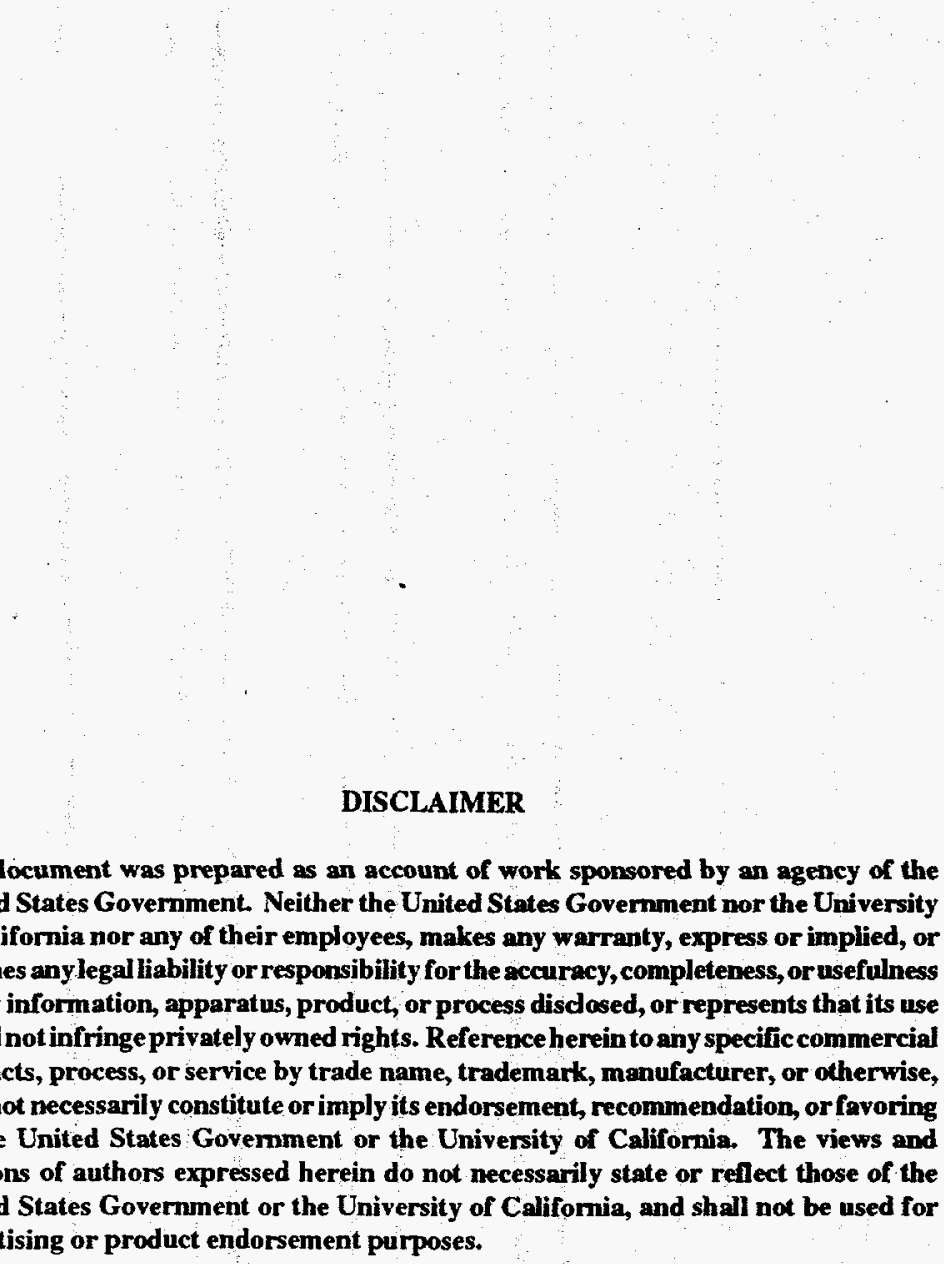




\section{DISCLAIMER}

Portions of this document may be illegible in electronic image products. Images are produced from the best available original document. 


\title{
Using emissivity-corrected thermal maps to locate deep structural defects in concrete bridge decks
}

\author{
Nancy. K. Del Grande and Pbilip F. Durbin \\ Lawrence Livermore National Laboratory, \\ P.O. Box 808, Livermore CA 94551
}

\begin{abstract}
Dual-band infrared (DBIR) thermal imaging is a promising, non-contact, nondestructive evaluation tool to evaluate the amount of deteriorated concrete on asphalt-covered bridge decks. We conducted proof-of-principle demonstrations to characterize defects in concrete structures which could be detected with DBIR thermal imaging. We constructed two identical concrete slabs with synthetic delaminations, e.g., 1/8-in. thick styrofoam squares, implanted just above the 2-in.-deep steel reinforcement bars. We covered one of the slabs with a 2-in. layer of asphalt. We mounted the DBIR cameras on a tower platform, to simulate the optics needed to conduct bridge-deck inspections from a moving vehicle. We detected 4-in. implants embedded in concrete and 9-in. implants embedded in asphalt-covered concrete. The midday (above-ambient) and predawn (below-ambient) delamination-site temperatures correlated with the implant sizes. Using DBIR image ratios, we enhanced thermal-contrast and removed emissivity-noise, e.g., from concrete compositional variations and clutter. Using the LINL/VIEW code, we removed the asphait thermal-gradient mask, to depict the 4-in. deep, 9-in. square, concrete implant site. We plan to image bridge deck defects, from a moving vehicle, for accurate estimations of the amount of deteriorated concrete impairing the deck integrity. Potential longterm benefits are affordable and reliable rehabilitation for asphalt-covered decks.
\end{abstract}

\section{INTRODUCTION}

There are over 575,000 bridges greater than 20 feet in length carrying public roads. Of these bridges, about 200,000 are deficient in some way. Whereas most bridge inspections have provided visual data of surface features, litule or no data exist to indicate hidden damage affecting the structural integrity of asphalt-covered concrete bridge decks. To mitigate this, the Federal Highway Administration (FHWA) is sponsoring a few feasibility studies to evaluate promising systems which could provide this data. During 1994, the FHWA sponsored LLNL to conduct Phase I of a feasibility study to evaluate dual-band infrared (DBIR) thermal imaging for concrete bridge dock inspections.

The Lawrence Livermore National Laboratory has pioneered the use of dual-band infrared (DBIR) thermal imaging with image correction algorithms to detect subsurface features. By removing emissivity noise, the DBIR method typically provides a factor of ten better signal-to-noise (S/N) compared to the (S/N) for conventional single-band infrared (SBIR) methods. This clarifies interpretation of heat flow anomalies from subsurface features, e.g., underground objects and suructural defects. Previous applications of DBIR imaging depicted:

- geothermal aquifers under 6 to 60 meters of dry soil 1,2,

- cemetery walls, trenches and a building foundacion under $80 \mathrm{~cm}$ of asphalt and debris ${ }^{3}$.

- buried mines, rocks and objects under 1 to $20 \mathrm{~cm}$ of disturbed sand, soil, or sod ${ }^{3-9}$,

- airframe material-loss defects from corrosion under 1 or $2 \mathrm{~mm}$ of exposed aluminum skin 9-14.

We describe the Phase I feasibility study of DBIR thermal imaging for concrete bridge deck inspections. DBIR thermal imaging has the potential to precisely depict surface thermal panterns at the sites of subsurface defects in large manmade structures. These thermal patterns imply the defect site, size and amount of damaged material with heat transfer properties which differ from those of the host material.

\section{PRECISE EMISSIVITY-CORRECTED DBIR THERMAL IMAGING METHOD}

We discuss an adaptation of the patented DBIR thermal imaging method for concrete bridge deck inspections. ${ }^{15}$ We use DBIR cameras, which scan naturally-heated targets, at infrared waveiengths of 3-5 $\mu \mathrm{m}$ and 8-12 $\mu \mathrm{m}$. DBIR image ratios enhance surface temperature contrast and remove the mask of surface emissivity noise, e.g., from stains, lane markers, surface roughness, object-clutter and concrete compositional variations. By distinguishing precise temperature differences from emissivity noise, we clarify interpretation of subtle heat flow anomalies from deep concrete delaminations above the top reinforcing steel bar in concrete bridge decks. DBIR image ratios, e.g., which provide improved temperanure contrast, and tag emissivity noise, are based on an expansion of Planck's radiation law. 16

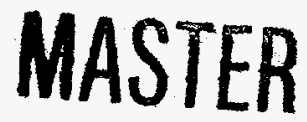


The results of the expansion are:

$$
I_{\lambda}-e_{\lambda} T^{50 / \lambda}
$$

where $I_{\lambda}$ is the intensity at a given wavelength, $e_{\lambda}$ is the emissivity at that wavelength, $T$ is the absolute temperature in Kelvin and $\lambda$ is the wavelength in micrometers. We can obtain high-contrast normalized temperature maps by computing $D B R$ image ratios for a greybody surface where es $=e_{10}$ :

$$
\frac{I_{5}}{I_{10}}=\frac{e_{5} T^{50 / 5}}{e_{10} T^{50 / 10}}=\frac{e_{5}}{e_{10}} T^{5} \text { and }(T / T a v)^{5}=(S W / S W a v) /(L W / L W a v)
$$

We can obtain normalized emissivity-noise maps by computing the DBIR emissivity ratios to contrast non-greybody features:

$$
\frac{\left(I_{10}\right)^{2}}{I_{5}}=\frac{\left(e_{10}\right)^{2}\left(\mathrm{~T}^{5}\right) 2}{e_{5} \mathrm{~T}^{10}}=\frac{\left(e_{10}\right)^{2}}{e_{5}} \text { and E-ratio }=(L W / \mathrm{Wav})^{2} /(\mathrm{SW} / \mathrm{SWav})
$$

where $\mathrm{SW}$ is the short-wavelength intensity (e.g., I5), SWav is the average value of the pixels in $S W, L W$ is the long wavelength intensity (e.g., I10) and $\mathbf{L W a v}$ is the average value of the pixels in $\mathbf{L W}$.

We scan concrete slabs at infrared wavelengths of 3-5 $\mu \mathrm{m}$ and $8-12 \mu \mathrm{m}$ to enhance surface temperaure contrast and remove the mask of surface emissivity noise, e.g., from oil, grease, paint, rocks, wood, plastic, metal and concrete compositional differences, for improved concrete bridge deck inspections. 13.14.17 This clarifies interpretation of subtle heat flow anomalies associated with subsurface delamination sites which heat and cool differently than the surrounding host (concrete) materials.

\section{APPLICATION OF DBIR THERMAL IMAGING FOR LARGE CONCRETE STRUCTURES}

Concrete slabs provided surrogate concrete bridge deck sections for the purpose of our feasibility study. We conducted field tests from a tower platform, using optics needed for bridge deck inspections from a moving plafform, where the IR cameras would be about 14 feet above the pavement. Our tests were used to: (1) optimize the DBRR system response to thermal signature differences between normal and defective concrete structures; and (2) clarify interpretation of subsurface cracks, voids and delamination sites which are typically masked by emissivity noise, e.g., from oil, grease, paint, rocks, wood, plastic, metal and concrete compositional variations. The DBIR system allows us to remove the emissivity-noise mask.

We mounted the Agema 880 DBIR camera system on a tower platform, overlooking two large concrete test slabs, one of which was covered with a two-in. layer of asphalt See Figure 1. The DBIR camera detectors were Hg-Cd-Te (at 8-12 $\mu \mathrm{m})$ and InSb (at 3-5 $\mu \mathrm{m}$ ). DBIR images were recorded on the hard drive of the Agema 880 12-bit digital image processing system, which was housed inside a trailer, at the ground station, and backed up for further processing on the SGI workstation.

Figures 1 and 2 show photos of Slab A and Slab B, and the layout of the synthetic delaminations. Two square, 6 feet on-a side, 7.5 inches thick, concrete test slabs A and B were cast with five variable-size styrofoam implants, 2 inches below the surface, representing synthetic delamination sites in surrogate concrete bridge deck structures. Slab A and Slab B were tested on January 29 with bare, concrete surfaces. During March, Slab A was covered with a 2 inch thick layer of asphalt and had one additional delamination added at the asphalt-concrete interface. During April, both slabs were remeasured to determine the effects of the asphait cover and of surface clutter. Figure 3 shows Slab B temperature readings which were recorded with thermistors. Tables 1 to 4 apply to the size and depth of the implants and the temperature-differences which were generated.

Table 1. Concrete delamination sites, dimensions and depth beneath concrete surface for Slab A and Slab B before and after resurfacing Slab A with a 2-inch layer of asphalt and placing a delamination at the asphalt/concrete interface. See Figure 2.

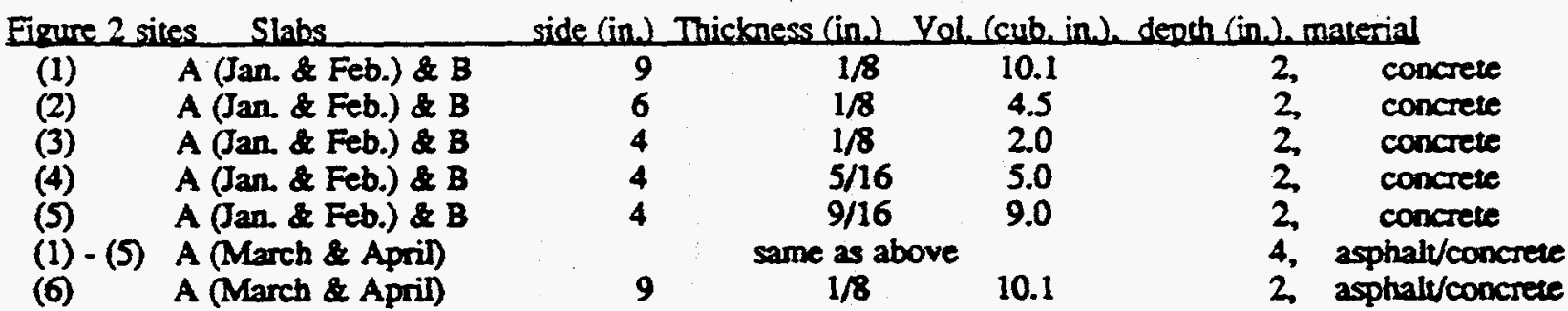


The Figure 2 diagrams show thermistor probe sites where we recorded concrete temperatures, e.g., above and below the styrofoam at $X$, at three shallow depths at $Y$ and at the surface at $Z$. Also, in Figure 2, are consecutive alphabetic letters shown counterclockwise, along the slab perimeters, which mark the sites of the surface object clutter described below.

(A) rusty steel pan with hole at center placed at top left side of slab;

(B) wood painted white at top with grease at bottom placed at bottom left side of slab;

(C) stainless steel plate placed at bottom center of slab;

(D) plastic road markers placed at bottom right of slab;

(E) rock placed at top right of slab.

Table 2. Delamination sites with above-ambient, day minus night, temperature differences: $\Delta \mathrm{T}\left({ }^{\circ} \mathrm{C}\right)$. The concrete data for Slab A and Slab B (taken in January) and Slab B (taken in April) were averaged, since $\Delta T$ was not very sensitive to solar insolation. See Figure 3. The resurfaced Slab A data were taken in April after Slab A had a 2-inch surface-asphalt layer.

\begin{tabular}{lcrrrr} 
Site & Slabs & $\begin{array}{c}\text { Defect Volume } \\
\text { (cub.in.) }\end{array}$ & $\begin{array}{c}\text { Mean } \Delta T(s) \\
\text { deg.C }\end{array}$ & $\begin{array}{c}\text { Depth } \\
\text { (in) }\end{array}$ & $\begin{array}{c}\text { Host } \\
\text { material }\end{array}$ \\
\hline & & & & & \\
(1) & A (Jan. \& Feb.) \& B & 10.1 & $3.6(0.6)$ & 2 & concrete \\
(2) & A (Jan. \& Feb.) \& B & 4.5 & $2.0(0.2)$ & 2 & concrete \\
(3) & A (Jan. \& Feb.) \& B & 2.0 & $1.2(0.5)$ & 2 & concrete \\
(4) & A (Jan. \& Feb.) \& B & 5.0 & $1.7(0.4)$ & 2 & concrete \\
(5) & A (Jan. \& Feb.) \& B & 9.0 & $2.0(0.3)$ & 2 & concrete \\
(1) A (March \& April) & 10.1 & $0.9(0.3)$ & 4 & asphalvconcrete \\
(6) A (March \& April) & 10.1 & $5.2(0.3)$ & 2 & asphalVconcrete
\end{tabular}

Table 3. Temperatures (T) and measurement times (hrs : $\min$ ) taken from April $1994 \mathrm{DBR}$ thermal images

Target

Slab A ambient asphalt, spot 2

Slab B ambient concrete, spot 2

Asphalt minus concrete $\Delta \mathrm{T}$

Day minus night $\Delta T$

\begin{tabular}{rr} 
SW (3-5um) & $T(\operatorname{deg} C$ at hos:min) \\
\hline 43.5 (14:02); & $11.4(06: 17)$ \\
37.3 (14:03); & $10.9(06: 16)$ \\
6.2 (14:02); & $0.5(06: 10)$ \\
32.1 Slab A; & 26.4 Slab B
\end{tabular}

SW (3-5um) I(deg C) at (hrs:min)

$37.3(14: 03) ; \quad 10.9(06: 16)$

32.1 Slab A; 26.4 Slab B

\begin{tabular}{cc} 
LW (8-12 um) & Ideg O at (hrsimin) \\
\hline 44.0 (14:02); & $11.9(06: 17)$ \\
33.1 (14:03); & $10.9(06: 16)$ \\
10.9 (14:02); & $1.0(06: 16)$ \\
32.1 Slab A; & 22.2 Slab B
\end{tabular}

Table 4. Above ( + ) or below (-) ambient clutter-site temperatures, $T$ (deg C) from daytime (d) or nightime (n) DBIR images.

\section{Target}

(A) rusty steel pans, spot 0

(B) wooden objects painted white, spot 6

(B) greased wooden objects, spot 7

(B) greased wooden objects, spot 7

(D) plastic road markers, spot 9

(E) rock on Slab A, spot 5

(E) rock on Slab B, spot 5

SW $(3-5 \mathrm{um}) T$ (deg $\mathrm{C})$
$-6.5 \mathrm{~d} / \mathrm{n}$ average
$-6.1 \mathrm{~d} / \mathrm{n}$ average
$5.8 \mathrm{~d}-$ only average
-7.7 n-only average
$-5.0 \mathrm{~d} / \mathrm{n}$ average
$-2.5 \mathrm{Slab} \mathrm{A} / \mathrm{n}$ average
$1.6 \quad \mathrm{Slab} \mathrm{B} \mathrm{d} / \mathrm{n}$ average

$L W(8-12$ um) $T$ (deg $C)$
-16.8 d/n average
-7.0 d/n average
5.4 d-only average
-4.6 n-only average
-3.9 d/n average
-3.1 Slab A d/n average
2.9 Slab B d/n average

Figure 4 shows the uncovered, concrete thermal signatures, i.e., Slab B during the day, in Row 1, and night, in Row 2. We note that DBR thermal imaging depicted emissivity-noise from the concrete compositional differences, e.g., the ancmaly near the image centers in Column 4, Rows 1 and 2. This emissivity-noise would not have been distinguished from a delamination site had we used conventional SBIR thermography. We successfully depicted the 4-in. implants, 2-in. deep in bere concrete.

Image processing, shown in Figure 5, allowed us to depict the 9-in. implants, 4-in. deep, in asphalt-covered concrete. They were not adequately depicted in Figure 4, ie., for Slab A during the day, in Row 3, ar night, in Row 4. In Figure 6, we see evidence of a significant correlation between the concrete temperature differences, e.g., ranging from $0.5{ }^{\circ} \mathrm{C} \mathrm{m}^{\circ} \mathrm{C}$, and the corresponding volumes of the styrofoam implants which caused these difference, e.g., ranging from 1 to 10 cubic in. 


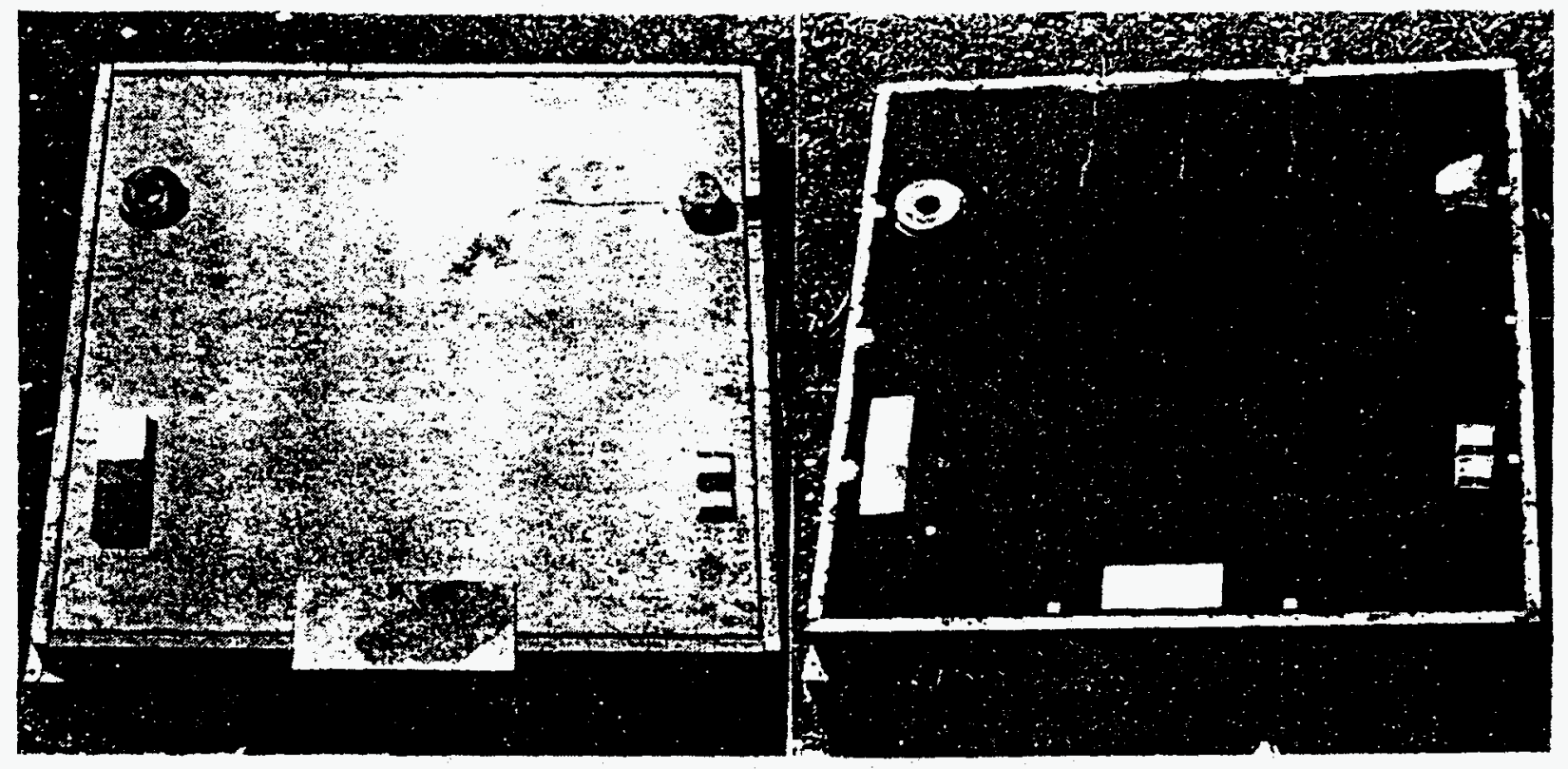

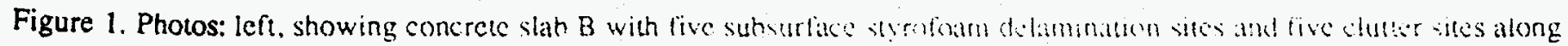

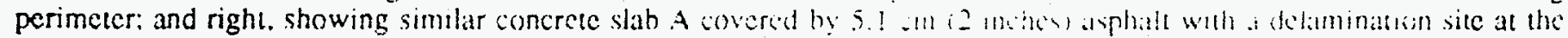

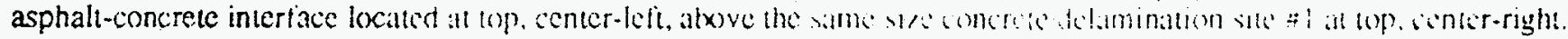

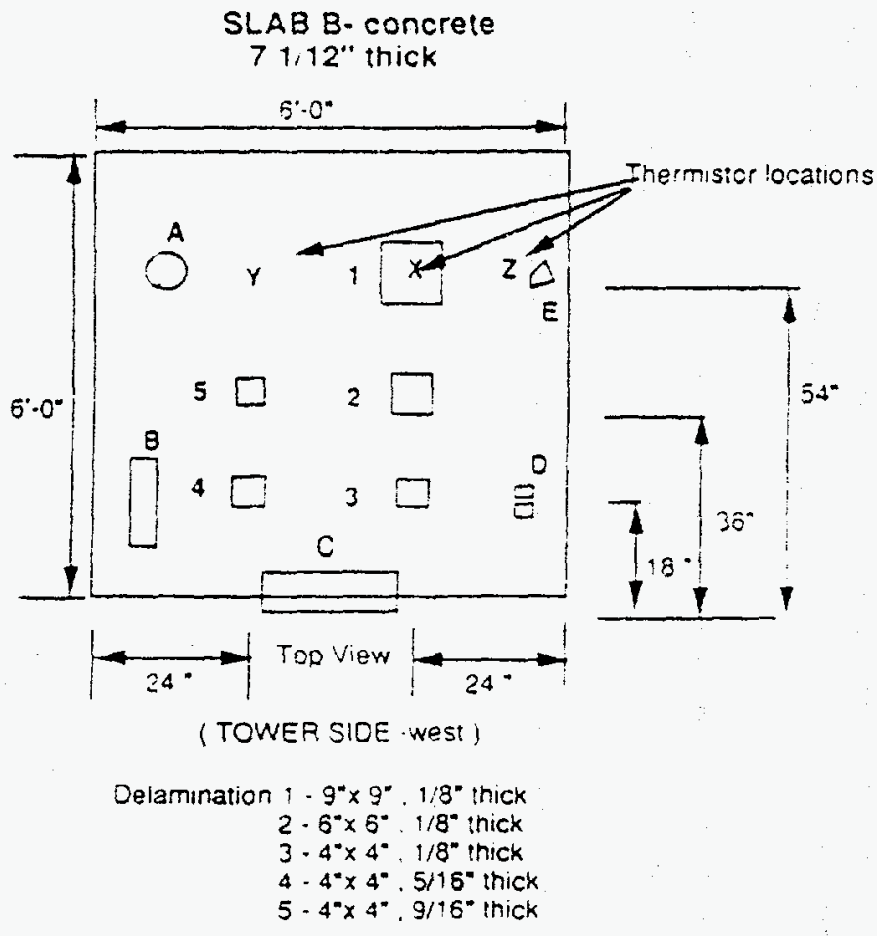

SLAB A-concrete-asphalt

$71: 2$ " thick concrete, with 2 " of aspnall
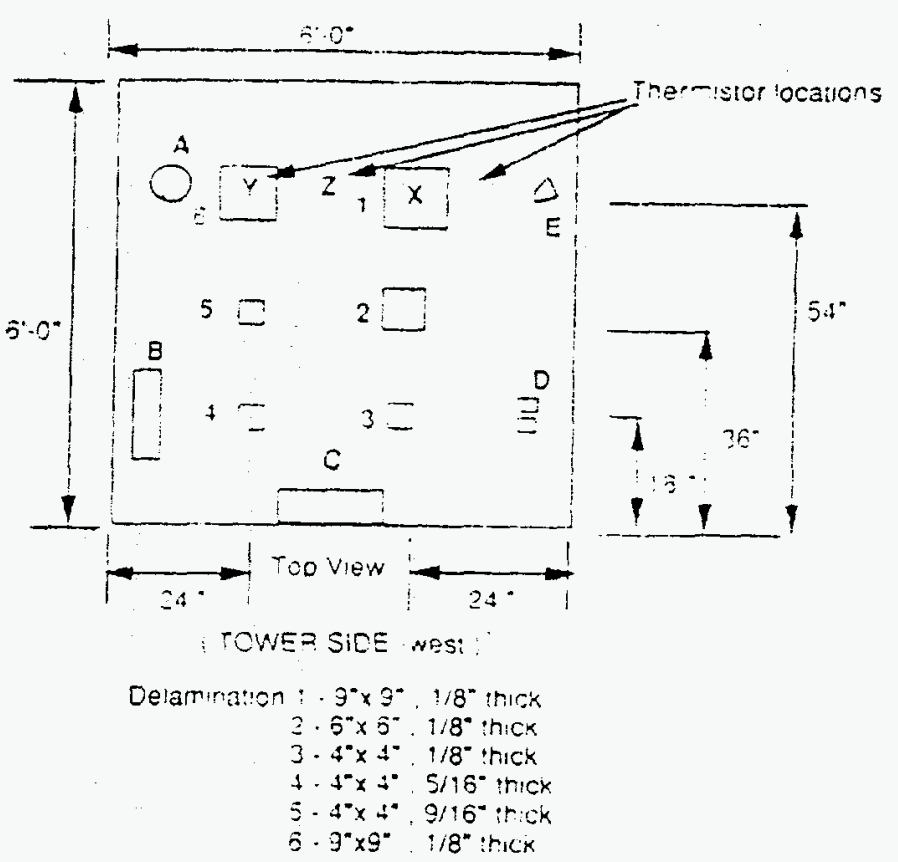

Figure 2. Diagram of concrete slabs used to measure the effects of subsurface delamination sites for a concrete bridge deck. 

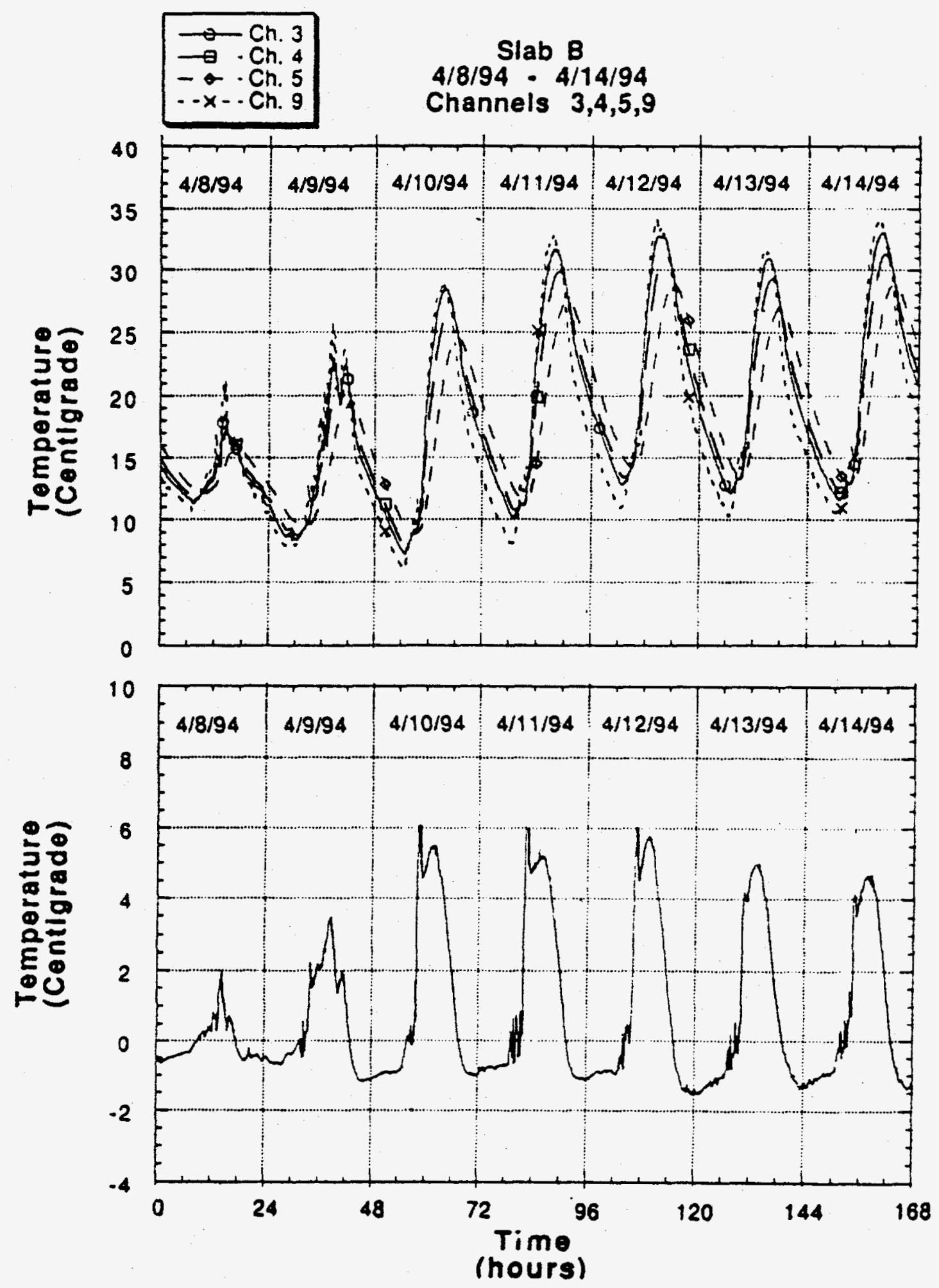

Figure 3. Above: concrete Slab B lemperatures, based on thermistor measurements at concrete sites without implants a depths of 1.25 in. (Ch. 3), 2.5 in. (Ch. 4), 6.0 in. (Ch. 5) and $O$ in. (Ch. 9). Below: surface temperature differences above the - in. square implant $(C h .10)$ relavive to ambient (Ch. 9) wero warmer during the day and cooler at night. 

Column 1
Coblume
Column 3
Column 4

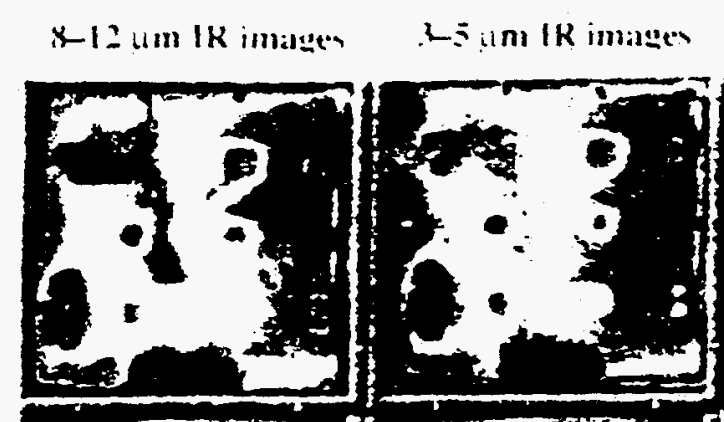

L5 $\$$ in IR images

DHIR high-contrant

DHIR emissivity-

temperature malps

moise maps
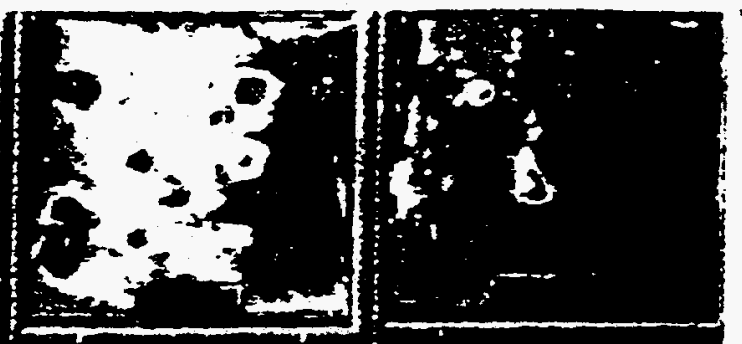

Concrete

Slab B

14:30 hrs
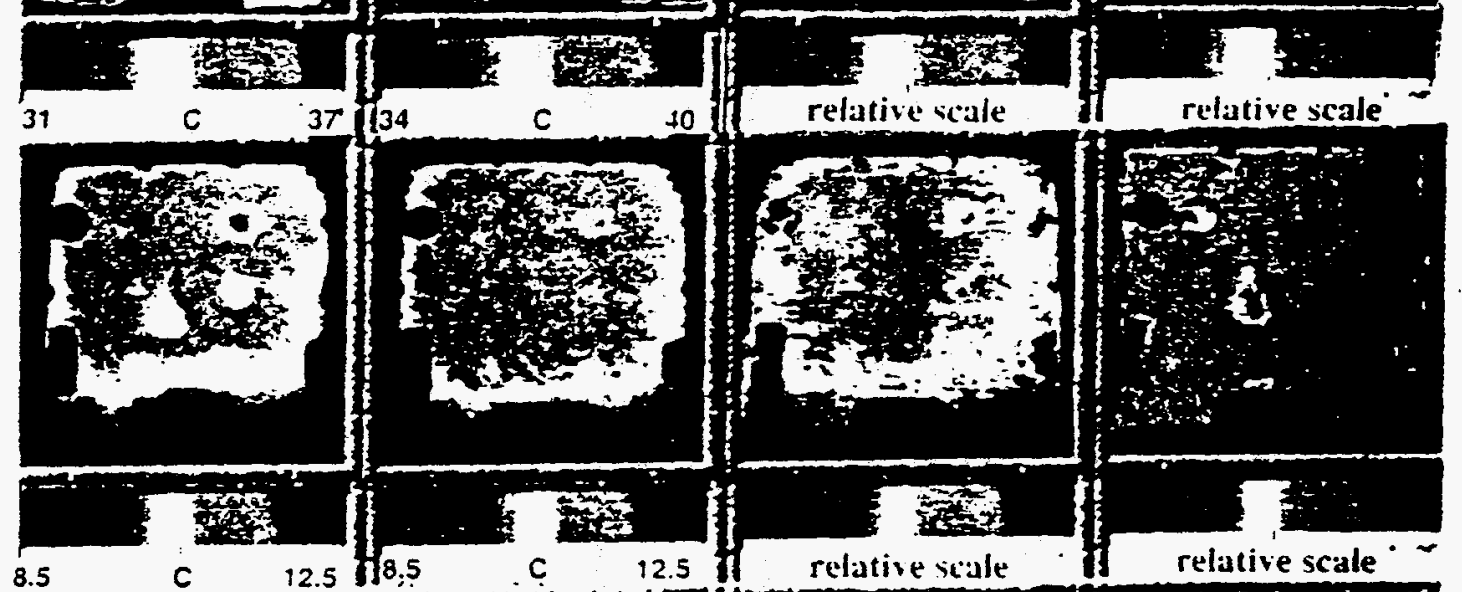

Concrete

Slab B

06:02 hrs
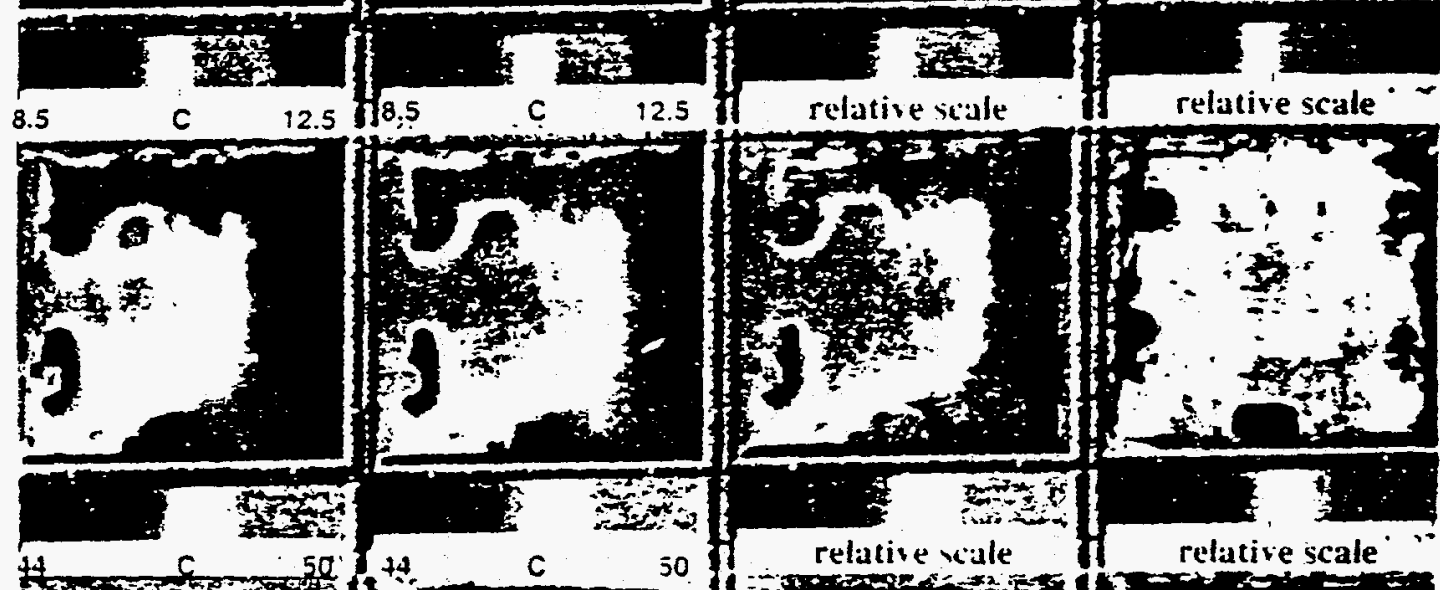

Paved

Concrete

Slab t

14:36 hrs
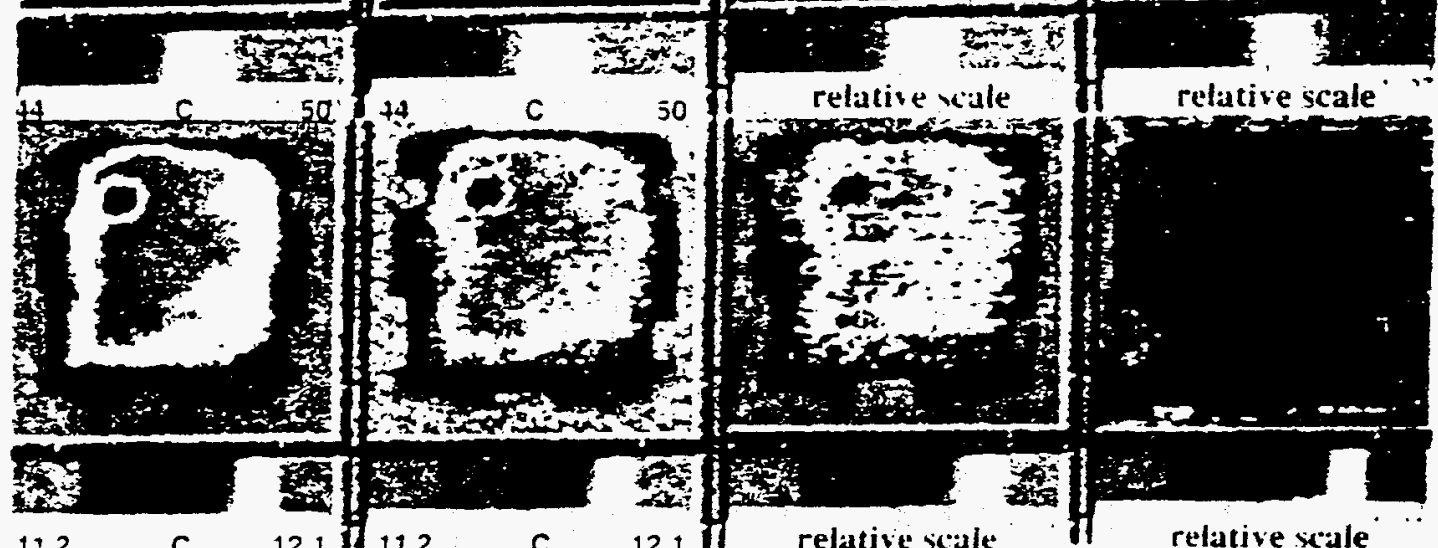

Paved

Concrete

Slab $A$

06: 17 hrs

Figure 4. Dusl-band infrared (DBIR) images taken Ipril 12. 1994, with a lawer-mounted Igema 880 System. Rows I and 2 show concrete Slab $B$ at 14:30 and $16: 112$ respectivety. Rows 3 and $f$ ihow paved concrete Slab $A$ at $14: 36$ and 16:17 respectively. Ipparent temperature maps were recorded at is 12 um (Column 1 ) and at 3-5 $\mu m$ (Column 2). High-contrast temperature maps ( Column 3 ) shou both delamination and clutter sites, whereas emissivity-noise maps i column fi show unly clutter sites. 

Cislumn 1
Colunin 2
(i)luime;
Inprocessed
8-12 un imalge:
IR images after
processing to enhance
t-inch-deep defiects
It intait:- alter
procening to tonhance
surfiat slutter

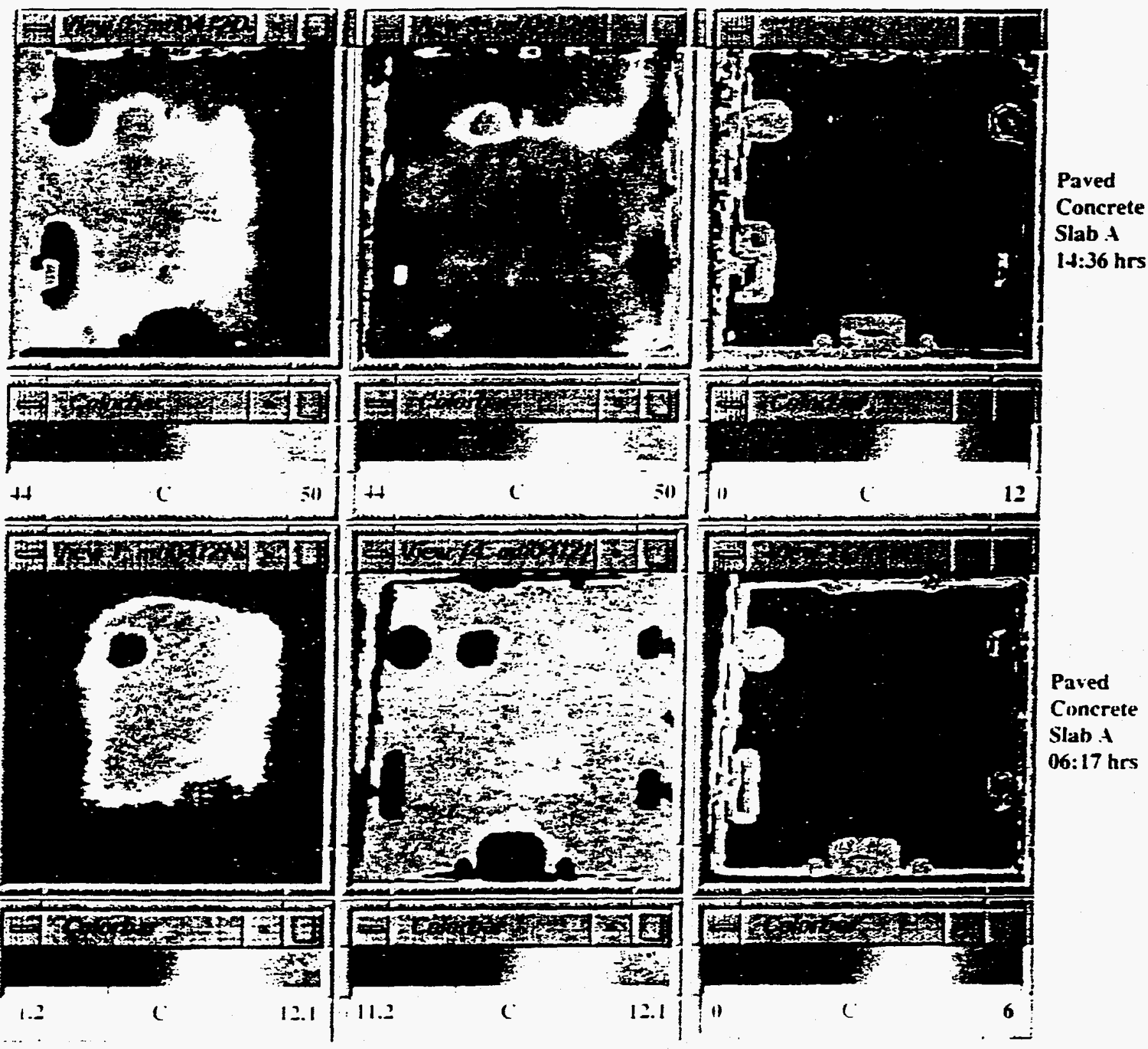

Figure 5 . (olumn 1. Day and night IR images before procesing. The asphalt pas ement mask. the t-inch-deep

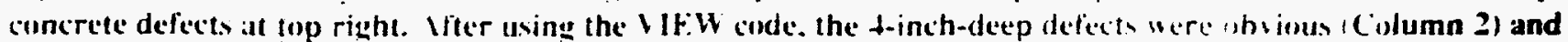
easily distinguished from surface chuter placed along the slab 1 perimeter : ( 


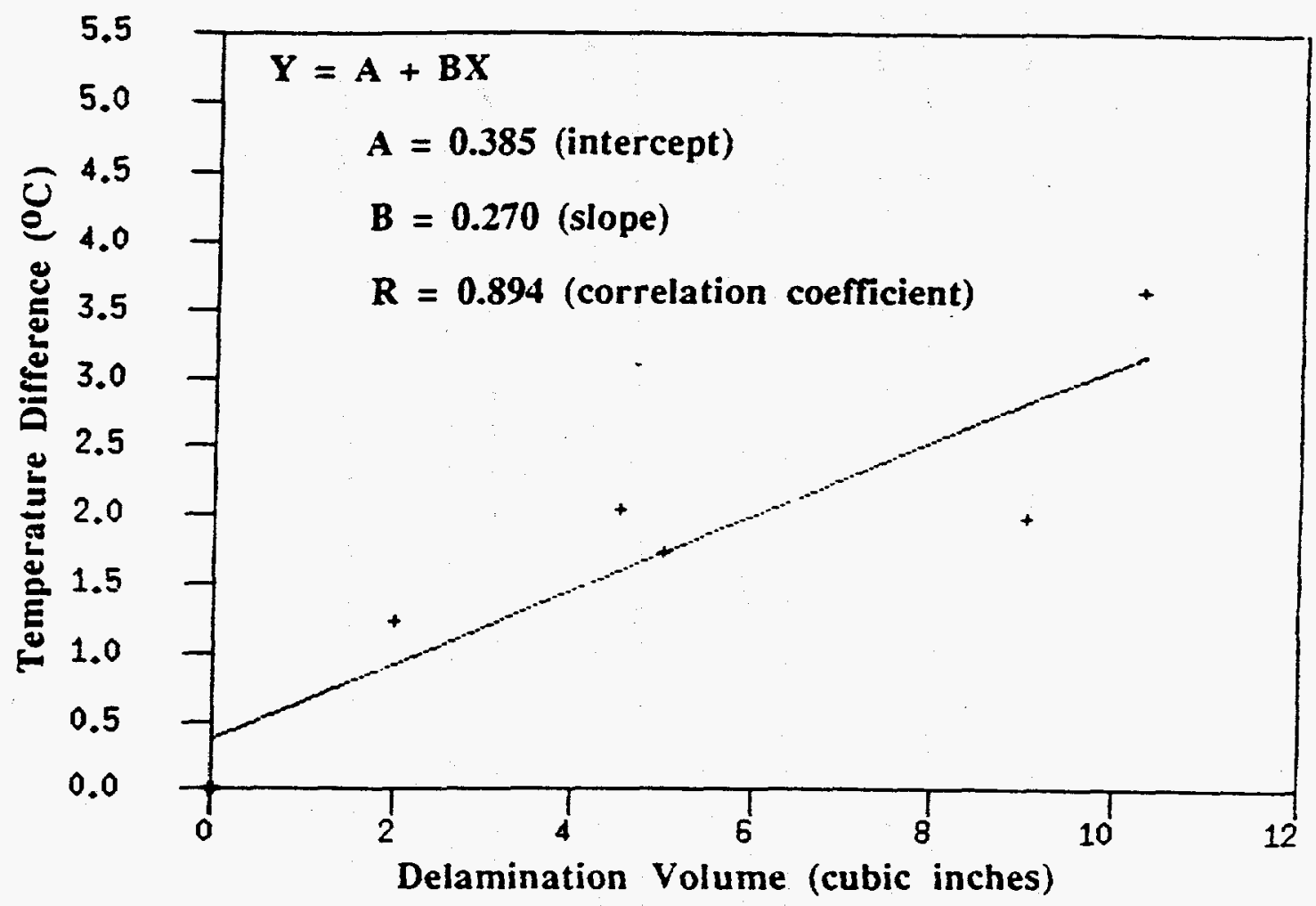

Figure 6. Average daytime (above ambient) minus nightime (below ambient) concrete temperawre differences varied as the styrofoam implant volumes. DBIR data were from the Jan. 29th tests, for Slabs A and B, and the Apr. 12th tests for Slab B.

\section{DBIR THERMAL IMAGING RESULTS AND IMPLICATIONS}

\subsection{Thermal signatures of synthetic delamination sites in concrete, Fig. 4, Rows 1 and 2}

The images shown in Figure 4 look alike when recorded at 8-12 $\mu \mathrm{m} \mathrm{LW}$ (Column 1) and 3-5 $\mathrm{mm} \mathrm{SW} \mathrm{(Column} \mathrm{2).} \mathrm{They}$ have similar apparent temperature maps, in Columns 1 and Column 2, and high-contrast temperature maps in Column 3. These maps differ significantly from their respective DBIR emissivity-ratio maps in Column 4. Both the high-contrast temperature maps and the emissivity-ratio maps have a relative scale, whereas the apparent temperature maps are scaled in degrees Celsius.

The pattem of five synthetic delamination sites shown in Figure 2 was apparent from images of Slab A and Slab B taken on January 29 (not shown) and images of Slab B taken on April 12. Slab A and Slab B thermal images were similar in January, but very different in April, since Slab A was overiaid with a 2 -in. thick asphalt layer before the tests were conducted in April.

The surface temperature gradients over the concrete delamination sites were more affected by the implant volumes, given in Table 1, than by the day-night temperature excursions, which differed significantly during January and April. For example, while most of the peak daytime surface temperatures varied from $28{ }^{\circ} \mathrm{C}$ to $34^{\circ} \mathrm{C}$, a $6^{\circ} \mathrm{C}$ spread, shown at the top of Figure 3, the corresponding daytime delamination-site temperature differences ranged, typically, from 5.0 to $5.8^{\circ} \mathrm{C}$, a $0.8^{\circ} \mathrm{C}$ spread.

\subsection{Thermal inertia signatures of synthetic delamination sites in concrete, Fig. 6}

Previous studies were made of thermal inertia signatures for buried mines. 7 Sites of disturbed soil above the buried mine had above-ambient temperatures during most of the day, and below-ambient temperatures during most of the night. Similar thermal inertia signatures are expected to tag deterioriated concrete. Within limitations, which havenot yet been specified, the daytime, nightrime, and daytime minus nighttime, concrese temperature excursions, e.g., from ambient, for deteriorated concrete, are expected to relate to the volume ( $\alpha$ amount) of deteriorated concrete. Figure 6 shows the correlation between the day-night concrete temperature excursions and the volume of the styrofoam implants. 
The reason for this is that the bulk thermal properties for defective, delaminated concrete, differ significanty from those of normal concrete. Defective and normal concrete have very different thermal inertia properties. They heat and cool at different rates from their surroundings. The thermal inertia, which is a measure of the resistance to temperature change, will be low for concrete sites with major delaminations affecting the structural integrity of the bridge deck, and high for normal concrete sites. Consequently, the daytime, nighttime, and daytime minus nightime, temperature excursions from ambient. are expected to increase with the size of the delaminations, and to quantify the amount of deterionated concrete.

\subsection{Emissivity noise signatures for surface compositional differences in concrete}

The DBIR emissivity-ratio maps depicted emissivity-ratio variations associated with five large surface clutter objects (along the perimeter) and three small thermistors encased in asphalt-like compounds (across the top, near the center of Slab A). The emissivity maps do not show surface temperature footprints at subsurface delamination sites. Instead, the emissivity maps show emissivity variations from staining, objects, or compositional variations, which apply to Slab B (concrete) or Slab A (asphalt-covered concrete) surfaces shown in Figure 4.

By tagging clutter sites on emissivity-ratio maps, we remove clutter from temperature maps at co-registered sites with anomalous surface temperatures. This lowers the probability of false calls which imply concrete damage where it does not exist By lowering the false-call probability, we increase the probability of correctly identifying temperature-map anomalies at subsurface delamination sites not depicted on the emissivity-ratio maps.

Metal objects are highly reflective, especially at 8 to $12 \mu \mathrm{m}$. As such, they appear from $5^{\circ} \mathrm{C}$ to $30^{\circ} \mathrm{C}$ cooler, than most other objects, during a clear, cool night. Slab B apparent temperature and DBR high-contrast temperaure maps, e.g.o in Figure 4, top two rows, show five delamination sites, shown in Figure 1, five clutter siles (along the perimeter) and a hidden anomaly near the center and upper left comer. Co-registered emissivity maps show the corresponding five clutter sites (along the perimeter) and the hidden anomaly where there is no corresponding visible stain or surface object. We believe the latter emissivity anomaly may be caused by obscured, surface compositional variations (e.g., metal particulates or sand) which are unrelated to subsurface defects.

Surface objects, which are visible during the day, can be recorded using a video camera on the platform used for the DBIR cameras. Video cameras have no way of seeing subule emissivity-noise effects. There is no way, apart from using DBIR imaging, to distinguish subule heat flow anomalies e.g., associated with deep delaminations, from emissivity variations, e.g., associated with the compositional changes of concrete. In Figure 4, Column 4, Rows 1 and 2, we successfully tagged emissivity clutter which had not visible indicators, and did not coincide with any known implant.

\subsection{Threshold detectability of concrete implants}

The styrofoam inserts in Slab A and Slab B, e.g., before Slab A was covered with a 2-inch layer of asphalt, had typical day and night surface temperatures which differed from their surroundings at implant sites as shown in Figure 4. The synthetic delamination sites were apparent for implants 1/8-in. thick and 4-in. or more on a side. During the day, the delamination sites and their ambient, typical surroundings, had relatively large temperature variations. At night, the converse was true, i.e., the delamination sites and their ambient, typical surroundings had small temperature variations.

It was easier to see the delamination signals during the day, although the daytime background noise was more of a problem. This was particularly true during windy and cloudy days which had less sunshine, and consequently less of a heat load during the day. At night, clouds obscur space cooling from the deep sky, typically at $-40^{\circ} \mathrm{C}$. Consequently, the below-ambient temperature excursions are reduced. Note the implant-site, nighuime, temperaure difference was $0.5^{\circ} \mathrm{C}$ on Apr. 8 , two or three times smaller than for the following six nights.

\subsection{Thermal gradient mask from asphalt aggregates}

The apparent temperanure and DBIR high-contrast temperature maps for the resurfaced (asphalt-covered) Slab A, e.g., see Figure 4, Rows 3 and 4, show one major defect at site (6) for the 9 inch on-a-side synthetic delamination placed at the top. left-of-center, 2-in. depth asphait-concrete interface. Also, there is a less pronounced indication of a deeper defect at site (1) for the 9 inch on-a-side synthetic delamination placed at the top, right-of-center, 4-inch depth, within asphalt-covered concrete. Corrections to remove a temperature gradient mask, from asphalt density variations, were successful, as shown in Figure 5. 
The 2-inch asphalt layer used to resurface Slab A for the measurements taken in April, 1994 appears to have density variations. We expect that these variations are caused partly by unevenly distributed aggregates and partly by unevenly compacted asphalt. For the measurements which were taken during midday, the asphalt variations produced a sizeable temperature gradient which masked deeper delamination sites. To remove this temperaure gradient, we used the VIEW code. Using VIEW, we removed the linear thermal gradient mask to reveal the 4-in. deep implant site in asphalt-covered concrete.

\subsection{Removing surface object clutter}

Clutter signals for objects along the perimeter of Slabs A and B are summarized in Table 4. With one exception, clutter site temperatures did not fall within 3 standard deviations (the statistical uncertainty) for Slab A asphalt and Slab B concrete surface temperatures. The exception was for the April 18, daytime, LW temperature of greased wood, which differed only 0.8 ${ }^{\circ} \mathrm{C}$ from the ambient asphalt Slab A surface temperature. Most clutter site temperatures were either off-scale by being 100 hot, e.g., red, or too cold, blue. They appeared very different from the concrete and asphalt-covered concrete surface temperatures. An algorithm was developed to sharpen the contrast between the surface clutter and the actual Slab A and Slab B surfaces. See Column 3 of Figure 5.

The DBIR imaging and VIEW image-processing system offers a unique combination of thermal resolution, defect characterization and clutter removal for improved interpretability. It produces corrected-temperaure maps and emissivity-ratio maps which distinguish delamination sites from surface clutter. During mid-April, the 4-inch deep asphalt-covered concrete delaminations produced surface temperature differences of $0.3{ }^{\circ} \mathrm{C}$ below-ambient at night and $0.6{ }^{\circ} \mathrm{C}$ above-ambient at midday. Surface stains (grease and paint), concrete compositional differences and objects (sand, rocks, wood, metal and plastic) produced DBIR emissivity ratios which differed from the host material, allowing us to suburact surface clutuer.

Density variations over the upper 2 -inch layer (from unevenly-compacted asphalt) produced a $2{ }^{\circ} \mathrm{C}$ temperature-gradient mast. Using VIEW to remove this mask, the details of which are shown in Appendix A, we were able to depict the deeper (and weaker) temperature gradients associated only with the 4-inch deep asphalt-covered concrete (synthetic) delaminations.

\section{SUMMARY, CONCLUSIONS AND FUTURE PLANS}

\subsection{Achieving feasibility study goals}

Using a borrowed, tower-mounted system (which simulated bridge-deck optics), we achieved our goal to image 4-inch deep synthetic delaminations (thin styrofoam inserts) in an asphalt-covered concrete slab placed beneath the tower. The DBIR imaging and VIEW image-processing system offers a unique combination of thermal resolution, defect characterization and clutter removal for improved interpretability. It produces corrected-temperature maps and emissivity-ratio maps which distinguish delamination sites from surface clutter.

\subsection{Depicting deep delamination sites}

During mid-April, the 4inch deep asphalt-covered concrete (synthetic) delaminations produced temperature differences of 0.3 ${ }^{\circ} \mathrm{C}$ below-ambient at night and $0.6^{\circ} \mathrm{C}$ above-ambient at midday. Surface stains (oil, grease and paint), compositional differences (within the concrete slabs) and objects (sand, rocks, wood, metal and plastic), produced DBIR emissivity ratios which differed from the host material. Density variations over the upper 2-inch layer (from unevenly-compacted asphait) produced a $2{ }^{\circ} \mathrm{C}$ temperabure-gradient mask. Using VIEW to remove this mask, we were able to depict the deeper (and weaker) temperature gradients from concrete implants.

\subsection{Determining detectability}

We met all of the goals of a Phase I feasibility study to evaluate DBIR thermal imaging for asphalt-covered concrete bridge deck inspections. We depicting 4-in. deep, 9-in. square, styrofoam implants in asphalt-covered concrete slabs used as surrogate bridge decks. We mapped 2 in. deep, 4-in. square, styrofoam implants in uncovered concrete. The threshold size and depth for siting concrete delaminations, in asphalt-covered concrete structures, had not been accurately determined prior to the present investigation. Using DBIR thermal imaging, we tagged and removed emissivity noise, e.g., from compositional variations in concrete which would not have been possible with a conventional SBIR system. 


\subsection{Quantifying the amount of deck deterioration}

The use of emissivity-ratio maps to tag and remove clutter is unique at LLNL. Clutter occurs from stains, e.g., oil, grease or paint, concrete compositional variations, e.g., metal particulates or sand, and surface objects, e.g., rocks, gravel, wood, plastic or metal. We clarify interpretation of corrosion damage by removing the mask from clutter. The DBIR method, compared to conventional SBIR thermography, improves the signal-to-noise $(S / N)$ tenfold for siting synthetic delaminations above potentially corroded metal reinforcements in concrete. We expect concrete delaminations, e.g., more than 9 inches on-aside, to produce prominent surface thermal footprints from the deteriorated volume of concrete and the ensuing damage at the asphalt-concrete interface.

\subsection{Longterm potential benefits}

Affordable asphalt-covered bridge deck rehabilitation requires an NDI method to accurately estimate the amount of deteriorated concrete from delaminations, which result from corrosion of the steel reinforcing bars, placed at a depth of two inches beneath the surface of the concrete. We plan to conduct bridge deck demonstrations from a moving vehicle, for Phase 2 of the feasibility study. This is a logical extention of the investigation we successfully completed for Phase 1, e.g., by mapping synthetic delaminations under asphalt-covered concrete slabs. This may well lead to an accurate estimate of the amount of deteriorated concrete impairing the deck integrity. Potential longterm benefits are affordable, and reliable, rehabilitation for asphalt-covered docks.

\section{ACKNOWLEDGMENTS}

This work was performed under the auspices of the U.S. Department of Energy by the Lawrence Livermore National Laboratory under contract number W-7405-ENG-48 for the FHWA order number DTFH61-93-Y-00145. We thank S. Chase (FHWA) for valuable technical discussions, M. Lawrence and N. Nguyen for calibrated thermistor measurements, M. Gorvad and D. Schneberk for image processing, M. Carter, D. Fields, S. Lake and M. Finger for use of the Agema 880 DBIR system and S. Kuikami and G. Thomas for their support.

\section{REFERENCES}

1. Del Grande, N., "Airborne and Field Temperature Surveys Compared At Long Valley KGRA, California", Geothermal Resources Council Transactions 5, 71, 1978.

2. Del Grande, N. K., "Airborne Temperature Survey Maps of Heat Flow Anomalies for Exploration Geology", Proceeding of International Symposium on Remote Sensing of Environment. Second Thematic Conference on Remote Sensing for Exploration Geology Dec. 1982. Reprinted in Geothermal Resources Council Bulletin 14, p.3, 1985

3. Del Grande, N. K., G. A. Clark, P. F. Durbin, D. J. Fields, J. E. Hernandez and R. J. Sherwood, "Buried Object Remote Detection For Law Enforcement", Surveillance Technologies. SPIE Vol. 1479, 335, 1991.

4. Del Grande, N. K., "Temperature Evaluated Mine Position Survey (TEMPS) Application of Dual Band Infrared Methodology", Proceedings of the 1990 Meeting of the IRIS Specialty Group on Passive Sensors, IRIAVERIM sponsored symposium, 1990.

5. Del Grande, N. K., "Sensor Fusion Methodology for Remote Detection of Buried Land Mines", Proceedings of the 3rd National Symposium on Sensor Fusion. Orlando, Fl, Vol. 1, IIAC/ERIM, p.407, 1990.

6. Del Grande, N., "Airborne Detection Of Buried Minefields", Energy and Technology Review University of California LLNL Report, UCRL-52-000-91-12,9, 1991.

7. Del Grande, N. K. P. F. Durbin, M. R. Gorvad, D. E. Perkins, G. A. Clark, J. E. Hernandez and R. J. Sherwood, Apr. "Dual-band Infrared Capabilities for Imaging Buried Object Sites" in Broceedings of SPIE Conference 1942: Underground and Obscured Object Imaging and Detection, Ed. N. Del Grande, I. Cindrich and P. Johnson, Orlando FL, 1993. 
8. Clark, G. A., J. E. Hernandez, S. K. Sengupta, R. J. Sherwood, P. C. Schaich, M. R. Buhl, R. J. Kane, M. J. Barth, N. K. Del Grande, "Sensor Feature Fusion for Detecting Buried Objects" Proceedinos of SPIE Conference 1942: Underonound and Obscured Object Imaging and Detection. Ed. N. Del Grande, I. Cindrich and P. Johnson, Orlando FL. 1993.

9. Del Grande, N. K., P. F. Durbin and D. E. Perkins, "Dual-Band Infrared Imaging Applications: Locating Buried Minefields, Mapping Sea Ice and Inspecting Aging Aircraft", Beview of Progress in Ouantitative Nondestnuctive Evaluation Vol. 12. Ed. by D. O. Thompson and D. E Chimenti. Plenum Press, NY, 1993.

10. Del Grande, N. K., K. W. Dolan, P. F. Durbin, M. R. Gorvad, B. T. Komblum, D. E. Perkins, D. J. Schneberk and A. B. Shapiro, Three-Dimensional Dynamic Thermal Imaging of Structural Flaws by Dual-band Infrared Computed Tomography" in Broceedines of SPIE Conference 1942: Underomound and Obscired Object Imaging and Detection, Ed. Nancy Del Grande, Ivan Cindrich and Peter Johnson, Orlando FL, pp.207-215, Apr. 1993.

11. Del Grande, N. K., K. W. Dolan, P. F. Durbin, M. R. Gorvad and A. B. Shapiro, "Dynamic thermal tomography for nondestructive inspection of aging aircraft" in Broceedings of SPIE Conference 2001. Nondestructive Inspection of Aging Aircraft. Ed. Michael Valley, Albert Kobayashi and Nancy Del Grande, San Diego CA. July 1993.

12. Del Grande, N. K., "Dual Band Infrared Imaging for Quantitative Corsosion Detection in Aging Aircraft", Proceedings of the American Society for Nondestructive Testing (ASNT) Meeting, Long Beach CA. Nov. 1993.

13. Del Grande, N. K., and P. F. Durbin, "Dual-band infrared imaging to detect corrosion damage within airframes and concrete structures" in Broceedings of SPIE Conference 2245: Thermosense XVI: An Intermational Conference on Thermal Sensing and Imagine Diagnostic Applications, Ed. John R. Snell, Jr., Orlando FL, Apr. 1994.

14. Del Grande, Nancy K, and Philip F. Durbin, "Multi-use applications of dual-band infrared (DBIR) thermal imaging for detecting obscured structural defects" in Proceedings of SPIE Conference 2217A: Underoround and Obscured Object Imaging and Detection, Ed Nancy Del Grande, Ivan Cindrich and Peter Johnson, Orlando FL Apr. 1994.

15. Del Grande, N. K., "Method for Identifying Anomalous Terrestrial Heat Flows"; Patent No 4,005289.1977.

16. LeSchack, L. A, and N. K. Del Grande,"A Dual-Wavelength Thermal Infrared Scanner As A Potential Airborne Geophysical Exploration Tool", Geophysics 41, 1318. 1976.

17. Philip Durbin and Nancy Del Grande, "Dual-Band Infrared Imaging For Concrete Bridge Deck Inspection", Proceedings of Structural Materials Technology-An NDT Conference, Alantic City NJ, Feb. 1994. 